\title{
Anti-TNF agents for the treatment of active non-radiographic axial spondyloarthritis
}

\author{
I. Olivieri', S. D’Angelo ${ }^{1,2}$, C. Palazzi' ${ }^{1}$, P. Leccese ${ }^{1}$, A. Nigro' ${ }^{1}$, A. Padula ${ }^{1}$ \\ ${ }^{1}$ Rheumatology Department of Lucania, San Carlo Hospital of Potenza \\ and Madonna delle Grazie Hospital of Matera, Potenza and Matera; \\ ${ }^{2} \mathrm{PhD}$ Scholarship in Health Sciences, Department of Health Sciences, \\ University of Molise, Campobasso, Italy
}

\footnotetext{
$T^{\mathrm{k}}$
} he spondyloarthritis (SpA) complex includes ankylosing spondylitis (AS), reactive arthritis, psoriatic arthritis, arthritis related to inflammatory bowel disease and forms that do not meet established criteria for these definite categories which are designated as undifferentiated SpA.

In the early 1990s, two sets of classification criteria were suggested with the purpose to cover the whole clinical spectrum of SpA: the Amor criteria and the European Spondylarthropathy Study Group (ESSG) criteria.

Since a short time ago, patients with AS were identified by using the modified New York criteria which require the presence of sacroiliitis of grade II bilaterally or grade III to IV unilaterally on radiographs as an indispensable condition for the diagnosis.

In the last few years, the management of AS has improved a lot thanks to the anti-tumor necrosis factor (TNF) agents. These drugs reduce signs and symptoms of inflammation and improve quality of life and functional status although there is no evidence on their ability to block the progression of radiographic damage to the spine (1).

Recently, the ASAS developed and validated criteria for axial (2) and peripheral SpA (3) that are going to substitute the Amor and the ESSG criteria.

The axial criteria also include the nonradiographic (nr) form of $\mathrm{SpA}$ in which inflammation can be detected by magnetic resonance imaging (MRI). These classification criteria will extensively be used in clinical and epidemiological studies in the near future and have substituted the modified New York criteria in the updated
ASAS recommendations for the beginning of anti-TNF therapy (4) and the new ASAS/EULAR recommendations for the global management of AS (5).

The burden of the disease of $\mathrm{nr}$ axial $\mathrm{SpA}$ patients was similar to that of patients in the radiographic stage meeting the modified New York criteria for AS in a German study published in 2009 (6) but was considered quite different in another 2012 German research in which the lower proportion of male patient and the lower impact of inflammation were outlined in nr axial $\operatorname{SpA}(7)$.

These last data could be due to the percentage of nr axial $\mathrm{SpA}$ patient without progression to AS. Accordingly, recent data showed that the radiographic progression is strongly dependent on the presence of elevated CPR and/or ESR levels, syndesmophytes at baseline and smoking (8).

The use of anti-TNF in the nr stage could maybe prevent the development of the structural damage (1). However, so far no drug has been approved for nr-axSpA.

In 2008, Haibel et al. published the first double-blind placebo-controlled study on TNF inhibitors in patients with nr-axSpA (9). Forty-six patients with active axial SpA were randomized to receive placebo or adalimumab every other week for 12 weeks followed by an open extension up to week 52. The primary endpoint was the achievement of the ASAS40.

Secondary endpoints included percentage of patients achieving BASDAI50, ASAS20, ASAS partial remission and the mean improvement in disease activity measures, physical function and HRQoL. After $\overline{\text { Corresponding author: }}$ Carlo Palazzi

Rheumatology Department of Lucania Via Potenza, 3 - 75100 Matera, Italy E-mail: kaps57@virgilio.it 
12 weeks of therapy, $54.5 \%$ of the adalimumab-treated patients achieved ASAS40 response, $68.2 \%$ ASAS 20 response and $22.7 \%$ ASAS partial remission response. Corresponding percentages in the placebo-treated patients were $12.5 \%, 25 \%$ and 0 , respectively. Clinical improvements achieved in the adalimumab group were maintained through the 52 weeks.

Expectedly, percentages of achievement of ASAS40, ASAS20 and ASAS partial remission responses increased greatly and significantly in the placebo-group after switching to adalimumab. Young age $(\leq 30$ years) and an increased CRP concentration $(>6 \mathrm{mg} / \mathrm{L})$ at study entry were the best predictors of achieving ASAS40 response. Serious adverse events were experienced by 5 patients, none of which was related to the drug.

The conclusion of the study was that adalimumab is efficacious and safe in patients with nr-axSpA. Two further randomized double-blind studies on anti-TNF agents in nr-axSpA were published $(10,11)$. In the first, 40 HLA-B27-positive patients with recent-onset inflammatory low back pain, active disease as measured by BASDAI and sacroiliac joint bone edema on MRI were randomized to receive infliximab at a dose of $5 \mathrm{mg} / \mathrm{kg}$ or placebo at $0,2,6$ and 12 weeks. MRI scans were performed at baseline and at 16 weeks and scored blindly (10). Clinical outcomes included BASDAI, BASFI, Ankylosing Spondylitis Quality of Life (ASQoL) and ASAS responses. A significant mean reduction of the used total MRI score from baseline to week 16 was seen in patients treated with infliximab than in those treated with placebo. A significant improvement was also observed for changes from week 0 to week 16 in BASDAI, BASFI, and ASQoL in the infliximab group.

A significant greater percentage of patients treated with infliximab achieved ASAS40, ASAS 5/6 and ASAS partial remission responses. In the second study, 76 patients with bone marrow edema in either the sacroiliac joints or the spine were randomized to etanercept or sulfasalazine (11). MRI was performed at weeks 0,24 and 48 and scored blindly. In the etanercept group, the reduction of the sacroiliac joint and spine scores were significantly larger compared with the group with sulfasalazine. Fifty per cent of the etanercept-treated patients reached clinical remission versus $19 \%$ of those with sulfasalazine.

Recently, the results of the ABILITY-1 study were published (12). Patients enrolled in this research met the ASAS classification criteria for $n r-a x S p A$ and had BASDAI $\geq 4$, total back score pain $\geq 4 \mathrm{~cm}$ (10 cm visual analogue scale) and inadequate response or intolerance or contraindication for NSAIDs.

All subjects were randomized to adalimumab (40 mg fortnightly) (91 patients) or placebo (94 patients). The primary endpoint was the ASAS40 response at week 12. Efficacy assessment included BASDAI and Ankylosing Spondylitis Disease Activity Score (ASDAS).

A significant higher percentage of patients treated with adalimumab achieved the primary endpoint and the improvement of other clinical and MRI (Spondyloarthritis Research Consortium of Canada - SPARCC - index) measures in comparison with patients treated with placebo. Young age and an increased CRP concentration level were predictors of achieving ASAS40 response. Safety analyses revealed similar results in the adalimumab and placebo groups.

The goal of treatment of axial SpA is to obtain the suppression of symptoms but also the prevention of structural bone damage and of ankylosis.

The studies on anti-TNF agents in longstanding axial disease have demonstrated that the structural damaged cannot be prevented and that it is independent from the presence of absence of inflammatory activity (13-15). A great effort should be done to increase the referral of every axial $\mathrm{SpA}$ patient to the rheumatologist. The therapeutic intervention in the early phases of the disease could maybe prevent the start of the periosteal activation (16). Should this hypothesis be confirmed every patient with active nr-axSpA should be promptly treated with TNF inhibitors in order to avoid structural damage. 


\section{REFERENCES}

1. Sieper J, Appel H, Braun J, Rudwaleit M. Critical appraisal of assessment of structural damage in ankylosing spondylitis: implication for treatment outcomes. Arthritis Rheum. 2008; 58: 649-56.

2. Rudwaleit M, van der Heijde D, Landewé R, et al. The development of assessment of Spondyloarthritis international Society classification criteria for axial spondyloarthritis (part II): validation and final selection. Ann Rheum Dis. 2009; 68: 777-83.

3. Rudwaleit M, van der Heijde D, Landewé R, et al. The assessment of Spondyloarthritis International Society classification criteria for peripheral spondyloarthritis and for spondyloarthritis in general. Ann Rheum Dis. 2011; 70: 25-31.

4. Van der Heijde D, Sieper J, Maksymovich WP, et al. 2010 update of the international ASAS recommendations for the use of anti-TNF agents in patients with axial spondyloarthritis. Ann Rheum Dis. 2011; 70: 905-8.

5. Braun J, van der Berg R, Baraliakos X, et al. 2010 update of the ASAS/EULAR recommendations for the management of ankylosing spondylitis. Ann Rheum Dis. 2011; 70: 896-904.

6. Rudwaleit M, Haibel H, Baraliakos X, et al. The early disease state in axial spondylarthritis: results from the German Spondyloarthritis Inception Cohort Arthritis Rheum. 2009; 60: 717-27.

7. Klitz U, Baraliakos X, Karakostas P, et al. Do patients with non radiographic axial spondylarthritis differ from patients with ankylosing spondylitis? Arthritis Care Res. 2012; 64: 1415-22.

8. Poddubnyy D, Sieper J. Radiographic progression in ankylosing spondylitisd/axial spondyloarthritis: how fast ad how clinically meaningful? Curr Opin Rheumatol. 2012; 24: 363-9.
9. Haibel H, Rudwaleit M, Listing J, et al. Efficacy of adalimumab in the treatment of axial spondyloarthritis without radiographically defined sacroiliitis. Arthritis Rheum. 2008; 58: 1981-91.

10. Barkham N, Keen HI, Coates LC, et al. Clinical and imaging efficacy of infliximab in HLA-B27-positive patients with magnetic resonance imaging-determined early sacroiliitis. Arthritis Rheum. 2009; 60: 946-54.

11. Song IH, Herman K, Haibel H, et al. Effects of etanercept versus sulfasalazine in early axial spondyloarthritis on active inflammatory lesions as detected by whole-body MRI (ESTHER): a 48-week randomized control trial. Ann Rheum Dis. 2011; 70: 590-6.

12. Sieper J, van der Heijde D, Dougados M, et al. Efficacy and safety of adalimumab in patients with non-radiographic axial spondyloarthritis - Results of a randomised placebo-controlled trial (ABILITY-1). Ann Rheum Dis. 2012. [In press].

13. Van der Heijde D, Salonen D, Weisman BN, et al. Assessment of radiographic progression in the spines of patients with ankylosing spondylitis treated with adalimumab for up to 2 years. Arthritis Res Ther. 2009; 11: R127.

14. Van der Heijde D, Landewe R, Baraliakos X, et al. Radiographic findings following two years of infliximab therapy in patients with ankylosing spondylitis. Arthritis Rheum. 2008; 58: 3063-70.

15. Van der Heijde D, Landewé R, Einstein S, et al. Radiographic progression of ankylosing spondylitis after up to two years of treatment with etanercept. Arthritis Rheum. 2008; 58: 1324-31.

16. Schett G. Structural bone changes in spondyloarthritis: mechanisms, clinical impact and therapeutic considerations. Am J Med Sci. 2011; 341: 269-71. 